\title{
Stages of Sensomotor Correction in Self-Regulation Development of Junior Schoolchildren
}

\author{
By Ekaterina Sedova* \\ Tatiana Goryacheva ${ }^{\dagger}$
}

Self-regulation development can be described as a process having multilayer causation. Following Nikolaeva (1991), we consider selfregulation as a system process, supporting relevant to the conditions changeability, flexibility of person's life activity. The self-regulation model (Nikolaeva, 1991) consists of three levels (the level of selfregulation of psychic states, the operational and the motivational levels). The aim of the current research was to influence on malfunction of the first level of self-regulation. The experimental group included 30 students in the age of eight-nine years having problems with school education because of instability and lack of concentration. The control group consisted of 32 children of the same age with the same problems not taking part in the intervention course. The basic diagnostics method was the Luria's neuropsychological battery of tests, adapted by Semenovitch (2002). The intervention method, applied in this study, was the method of sensomotor correction (Goryacheva, Sultanova, 2003). It is based on the Luria's theory of three functional blocks of brain (Luria, 1962) and focuses on normalization of first functional block of brain by means of motion. The correction process included four stages with special exercises (breathing, locomotory, oculomotor etc.) each one. Some basic exercises were performed throughout the whole intervention period. During eight months the children have been having two one-hour group sessions per week. Each group consisted of 6 persons. Comparison with the control group has shown that the sufficient positive changes of self-regulation level have taken place in the experimental group. Improving of school results, more pronounced in experimental group, also confirms that sensomotor correction is a powerful way of self-regulation development.

\section{Introduction}

Different aspects of self-regulation are nowadays in the focus of various psychological studies. Individual system of self-regulation integrates dynamic and

${ }^{*} \mathrm{PhD}$ Candidate, Moscow State University of Psychology and Education, Russia.

${ }^{\dagger}$ Associate Professor, Moscow State University of Psychology and Education, Russia. 
contextual, conscious and unconscious structures of personality. Following Nikolaeva (1991) we consider self-regulation as a system process, supporting relevant to the conditions changeability, flexibility of person's life activity.

The three-level model of self-regulation introduced by Nikolaeva (1991) helps to explain the connections between certain parts of this system. The first level is the level of self-regulation of psychic states, supporting the needed activation level. The second is the operational level, providing conscious planning, performance and correction of person's activities. The third motivation level - allows to realize the motives of activity and to control them. Figure 1 illustrates the interconnections between the levels (Sedova, Goryacheva, 2012).

Figure 1.Three-Level Model of Self-Regulation

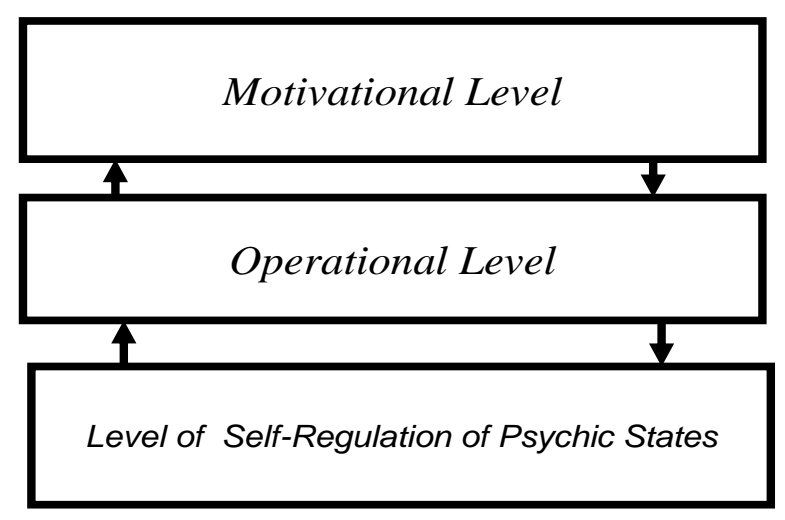

Various theories of self-regulation can be considered as relating to one or two levels of this model. Carver and Sheier's $(1981,1998,2000)$ theory describes behaviour as a process of movement towards the goal or away from anti-goal. Goals serve as reference values for feedback loops. Thus, the theory describes the interaction between motivational and operational level of self-regulation. The analysis of feedback loops can be referred to the operational level. The same conclusions can be applied to the theory of Konopkin (1980), describing the process of self-regulation also as a loop, consisting of six components: goal, conditions model, program of actions, success criterion, information about result, decision whether correction is needed. The process of the goal-setting corresponding motivational level of self-regulation is explained by the theory of Deci and Ryan (2000, 2002).

The development of self-regulation is still little-investigated. Some researchers suppose that forms of self-regulation in the age of four or five years are not the beginnings of this ability, they are based on the previous stages (Bezrukhih and Loginova, 2002). According to Sultanova (2005), the development of regulatory systems starts during the prenatal period, when stem and subcortical structures are forming, and consequently, they are vulnerable to a 
range of factors such as intoxication, hypoxia etc. Later low level of selfregulation causes problems in various spheres of life. Pelco and Reed-Victor (2007) confirmed the connection between poor self-regulation of emotions, attention, behaviour in early childhood and difficulties of school learning in later years. Gardner et al. (2008) found out that the adolescents with deviant behaviour have lower level of self-regulation than their peers not demonstrating antisocial tendencies. In a longitudinal research carried out on the sample consisting of 518 participants Crockett et al. (2006) showed that risky sexual behavior in the age of 16-17 years is associated with low level of self-regulation in the age of 8-9 years.

\section{Methodology}

\section{Research Goal}

The aim of current research was to influence on malfunction of the first level of self-regulation by means of sensomotor correction.

\section{Research Sample}

The experimental group included 30 students in the age of eight-nine years, with learning difficulties because of instability and lack of concentration, whose parents applied to the Centre of Psychodiagnostics and Psychocorrection of IBP, Moscow. The control group consisted of 32 children of the same age with the same problems not taking part in the intervention course.

\section{Research Methods}

The basic diagnostics method was the Luria's neuropsychological battery of tests, adapted by Semenovitch (2002). For every child we have also evaluated the Involuntary Self-regulation Index (ISI), depending on demonstrations such phenomena as muscle tone aberrations, synkineses, macro- and micrography etc. The Voluntary Self-regulation Index (VSI) depended on how a child followed the instructions, noticed and corrected his/her errors, whether he/she demonstrated impulsiveness or inertness. According to the value of VSI, estimated in our previous researches (Sedova, Goryacheva, 2012) the sample was divided into subgroups with medium and low level of self-regulation. There were no persons with high level of self-regulation neither in the experimental, nor in the control group at the first diagnostics. The data of school progress - good or poor results in learning - were collected.

The intervention method, applied in this study, was the method of sensomotor correction (Goryacheva, Sultanova, 2003). It is based on the theory of three functional blocks of brain and focuses on normalization of first functional block of brain by means of motion.

The effect of sensomotor correction is determined by the impact of motional and sensor components to the whole mind of the child. In his theory of motor control Bernstein (1967) showed that movement can not be organized only by efferent impulses. There should be a set of afferences, providing feedback and 
movement correction. From the point of view of brain organization those are different structures of analyzer systems (second block of brain) and afferent part of sub-cortical structures, connected to activation level and motivation processes. Structures, connected with behavior program and regulation of activity (third block of brain), and efferent part of sub-cortical structures, connected with action organization (first block of brain) form the efferent system. That means the elements of all the three blocks of brain are included in the functional system.

In the process of sensomotor correction, special exercises (locomotor, oculomotor and breathing) help to achieve the normalization of central nervous system activation, to improve the status of sub-cortical structures and to develop the connections between different brain structures (cortical - sub-cortical, interhemispheric and others), that helps to improve the involuntary self-regulation functioning.

Following features of the intervention course are determined to develop the voluntary self-regulation skills:

- In the process of correction we try to bring control in the activities normally being extramental: breathing, crawling etc.

- We help the child to master relaxation skills

- During the intervention course a child has special home assignments

- As an addition to the main exercises we include into session rule games, games developing concentration etc.

We chose group form of sessions as in a group some features of sensomotor correction could be more effective, because of the elements of a game and of competition between the children. It also helps to show successful and unsuccessful ways of solving of a problem.

The method of sensomotor correction has some restrictions. The first is age: intervention is more effective for junior schoolchildren than for older ones. There also some contraindications: epilepsy, dorsal spine traumas etc.

\section{Stages of Correction}

The first task of the therapists, working with the groups, was to establish and maintain positive attitude towards the intervention. The children and the parents were informed about future work and possible difficulties.

After children have got to know each other it was important to create atmosphere of mutual confidence, to work out the feedback mechanisms and to make children learn the rules.

We introduced the system of encouragements and penalties. Every child had a small notebook with dates of sessions. If a child behaved him/herself at the session and did his/her best while doing the exercises we put a sticker against the session date. If there were any problems the child received some penal points and in the end of the session could go without a sticker. 
The children had to perform the set of exercises at home. Parents supposed to help them, that is why the parents were invited at the first session of every stage.

\section{First Stage}

The tasks of the first stage were practicing basic exercises and improvement of child-parent relations.

At this stage children were taught to perform breathing exercises, learned finger plays and practicing basic tonic and locomotor exercises, influencing the vestibular system, normalizing muscle tone and developing inter-hemispheric connections.

Most of the children had difficulties in the beginning of the course. At this stage parents' help was extremely important.

After 8-10 sessions we usually observe slight deterioration of a child's condition connecting with the reorganization of the Central Nervous System, sometimes it can cause problems with child's behavior and interaction in the group. But those demonstrations normally do not last longer than two weeks and than fade out.

In the end of first stage we should deal with the confrontation between the group members. It can be explained by the small group dynamics processes. Sometimes children get very aggressive towards their fellows and the therapist. To damp this process we propose children to lead a session by turns. It helps to enhance every child's authority and also make the children more attentive to the order and right performance of the exercises.

The home assignment of this stage was arrangement of regular exercises at home. This task was not as simple as in seems to be. To motivate the children we used the other set of stickers to be put in their notebooks if they confirm they were training every day between the sessions in the Centre.

\section{Second Stage}

At this stage the locomotor movements and stretching are in the focus. Those exercises are added to the main program.

By this time almost all the children managed to organize everyday home trainings, so we proposed them the next task as a home assignment. They should have planned their after-school activity, i.e. to make a schedule together with a parent and to indicate time for school homework, rest and of course include into it the correction exercises. In the end of the day they should have analyzed how they fulfill the schedule, what went wrong and why. In case of repeated difficulties parents could consult the specialists of the Centre.

\section{Third Stage}

The task of the third stage is dealing with pathological synkineses.

This stage includes two steps.

At the first step we teach a child to go on all fours in different ways, combining various movements of arms and legs, aiming to make arms and legs 
move separately. At the second step a child should go on all fours making different combination of movements of the head, eyes and tongue, for instance: left arm forward, head turned to the left, eyes and tongue to the right.

As a home assignment the children, who already started to plan their days with parents, could get more independence in making the schedule, but parents still were helping to control its fulfillment.

\section{Fourth Stage}

The task of the stage is continuing dealing with pathological synkineses and development of the adequate synergies.

At this stage children perform a lot of exercises for improving of interhemispheric interaction. We also add some exercises with a tennis ball for developing dexterity. Normally those exercises are not very difficult for the children.

The planning in families at this stage depended of their previous results in this field. In those families where the members have got used to making a schedule and to analyze its fulfillment, children could manage with this task themselves. For other kids the help of adults was still important.

\section{Research Results}

Comparison with the control group has shown that the sufficient positive changes of self-regulation level have taken place in the experimental group. Mann-Whitney U-Test was used and statistically significant differences were obtained when comparing the gap between first evaluation indexes values (before the intervention course) and the follow-up ones: for the ISI $p \leq 0,001$ and for the VSI $p \leq 0,016$.

Table 1. Diagnostics Results before and after the Intervention

\begin{tabular}{|c|c|c|c|c|}
\hline \multirow{2}{*}{ Subgroups } & \multicolumn{2}{|c|}{ Experiimental group } & \multicolumn{2}{c|}{ Control group } \\
\cline { 2 - 5 } & $\begin{array}{c}\text { First } \\
\text { diagnostics }\end{array}$ & Follow-up & $\begin{array}{c}\text { First } \\
\text { diagnostics }\end{array}$ & Follow-up \\
\hline $\begin{array}{c}\text { Good school results - high } \\
\text { level of self-regulation }\end{array}$ & 0 & 2 & 0 & 0 \\
\hline $\begin{array}{c}\text { Good school results - } \\
\text { medium level of self- } \\
\text { regulation }\end{array}$ & 3 & 5 & 6 & 7 \\
\hline $\begin{array}{c}\text { Good school results - low } \\
\text { level of self-regulation }\end{array}$ & 0 & 0 & 1 & 1 \\
\hline $\begin{array}{c}\text { Poor school results - medium } \\
\text { level of self-regulation }\end{array}$ & 7 & 15 & 17 & 14 \\
\hline $\begin{array}{c}\text { Poor school results - low } \\
\text { level of self-regulation }\end{array}$ & 20 & 8 & & 10 \\
\hline
\end{tabular}

In the experimental group we have found the rise of self-regulation level in fourteen cases. Four children demonstrated pronounced progress in learning: 
they left the subgroup with "poor school results" for the subgroup with good ones. In the control group we saw the same change just in one case and the rising of self-regulation level in three cases.

During the intervention course all the children of experimental group improved their school results, their teachers noted efficiency and concentration enhancement, successes in concrete kinds of learning activity: writing, calculations, problem solving etc.

Although all the children demonstrated positive results of intervention, the degree of success was different. On one hand that fact can be explained by the individual characteristics of every child. But we have also to mention the other very important factor, such as parents' support of the child and the combination of their patience and persistence.

\section{Conclusion}

The method of sensomotor correction is an effective way of dealing with self-regulation problems. It helps to improve functioning of the involuntary self-regulation as well as to develop voluntary self-regulation.

In case of unsatisfactory child-parent relationship in a family it is recommended to combine the sensomotor correction with other therapeutic methods helping to settle family conflicts. Although we underline the fact that the results of intervention are more pronounced if parents of a child take part in the intervention process, there've been no special diagnostic means to investigate parents' interference. This could be marked as a limitation of this research as well as the relatively small size of the research sample.

The directions of future researches in this field could concern studying changes of motivation during the intervention course, role of parents and implementing of technical means, e.g. EEG, for registering the effects of correction.

\section{Acknowledgments}

We would like to thank all the beautiful children and their parents, who consented to take part in the research and were working very hard during the intervention course, and our colleagues from the Centre of Psychodiagnostics and Psychocorrection of IBP for their support and advice.

\section{References}

Bernstein, N.A. 1967. The co-ordination and regulation of movements. Oxford: Pergamon Press.

Bezrukhih, M. M., \& Loginova, E. S. 2002. Age-specific features structure of selfregulation of activity in the age of 4-5 years. The World of Psychology, 2, 121127. 
Carver, C., \& Scheier, M. 1981. A control-system approach to behavioral selfregulation. Review of personality and social psychology (pp.107-140). Beverly Hills: Sage.

Carver, C., \& Scheier, M. 1998. On the self-regulation of behavior. N. Y.: Cambridge University Press.

Carver, C., \& Scheier, M. 2000. Perspectives of personality. Boston etc.: Allyn \& Bacon.

Crockett, L. J., Raffaelli, M., \& Shen, Y. L. 2006. Linking self-regulation and risk proneness to risky sexual behavior: Pathways through peer-pressure and early substance use. Journal of Research on Adolescence, 16(4), 503-525.

Deci, E., \& Ryan, R. 2002. Handbook of self-determination research. Rochester, N. Y.: University of Rochester Press.

Gardner, T. W., Dishion T. J., \& Connell, A. M. 2008. Adolescent self-regulation as resilience: Resistance to antisocial behavior within the deviant peer context. Journal of Abnormal Child Psychology, 36(2), 273-284.

Konopkin, O. A. 1980. Psychological mechanisms of self-regulation of activity. Moscow: Nauka.

Nikolaeva, V. V. 1991. On the psychological nature of alexithimia. Human Corporeality: interdisciplinary researches. Moscow: FO SSSR.

Pelco, L. E., \& Reed-Victor, E. 2007. Self-regulation and learning-related social skills: Intervention ideas for elementary school students. Preventing School Failure, 51(3), 36-42.

Ryan, R. M., Deci, E. L. 2000. Self-determination theory and the facilitation of intrinsic motivation, social development and well-being. American Psychologist, 55, 68-78.

Sedova, E., Goryacheva. T., 2012. Longitudinal study of self-regulation of junior schoolchildren. US-China Education Review, 2, 170-177.

Semenovitch, A. V. 2002. Neuropsychological diagnostics and correction in childhood. Moscow: Akademia.

Sultanova, A. S. 2005. Development of child psychics in prenatal period (pp. 142153). Reading book of perinatal psychology. Moscow: Izdatelstvo URAO. 